\title{
Discussion on the Training Mode of the "Chemical Engineering Production Technology" Skill Competition
}

Xinwen Zhang ${ }^{1, a^{*}}$, Shulan $\mathrm{Yu}^{1, \mathrm{~b}}$ and Changtao $\mathrm{Ge}^{1, \mathrm{c}}$

${ }^{1}$ Weifang Vocational College, Weifang, Shandong, 261041, China

*the corresponding author

Keywords: Chemical engineering production technology; Skills competition; Training

Abstract. The skills competition of the "chemical engineering production technology" of the national vocational college is a kind of event sponsored by the Ministry of Education, which is highly concerned and valued by the professional colleges and universities of chemical industry. By analyzing and summarizing the effective ways which are the "five stages" and "learning by doing, doing by learning" to guide students' training, the skills and qualities of teachers and students can be comprehensively promoted.

\section{“化工生产技术”技能大赛培训模式的探讨}

\author{
张新文，于淑兰，葛长涛 \\ 潍坊职业学院，山东省 潍坊 261041
}

摘要: 全国职业院校 “化工生产技术” 技能大赛是教育部主办一类赛事, 备受化工专业职业院校对此极大关注和高度重 视。通过分析及总结指导学生训练的有效方法: “五个阶段”，“学中做，做中学”全面提升师生技能和素质。

关健词: 化工生产技术; 技能大赛; 培训

\section{1 引言}

随着我国化学工业的蓬勃发展, 每年都需要大量的具有实操能力的化工总控工[1]; 随着化学工业自动 化程度越来越高，化工行业对化工技能型人才，尤其是高素质技术技能型化工人才的强劲需求。

“化工生产技术” 技能竞赛对于化工专业的学生来说是一个契机，是提高学生理论知识应用能力、实 践技能操作能力、团队协作能力指挥棒; 借助这个舞台, 学生有机会向社会展示自己的理论实力, 实践操 作技能实力和和妥善处理突发事件的实力[2]等等。自2008年, 我校组队参加中国石油和化学工业协会等主 办的全国石油化工技术类职业院校化工总控工技能竞赛，该赛事由 2012 年升级为国家教育部主办，是一类 赛事。经过几年的努力，我校的学生在本赛项中分别获得团体二等奖 5 项，三等奖4项，个人全能二等奖 8 项, 个人全能三等奖4项良好成绩。俗话说: “台上一分钟, 台下十年功”, 优异成绩的获得, 离不开科学、 高效、扎实、规范的训练。本人担任参赛代表队的指导教师, 全程指导训练和比赛, 颇有感触, 现将体会 总结如下:

\section{2 成立教练组，打造指导教师自身实力}

技能大赛从表面上看是在考核学生技能水平，其实是在考核教师水平，特别是指导教师的专业水平。 要培养出一支优秀的学生团队，必须有一个技术过硬、管理优秀的教练团队。化工生产技术技能大赛项目 包括理论知识（权重 $15 \%$ )、化工仿真操作（权重40\%)、精馏操作（权重45\%)。第一项是应知理论部分 [3], 考点多，包括各种化工单元操作、化工工艺、精细化工、化工仪表、化工机械、化工自动化等相关课程共 
20 多个方面的内容。后两项是应会部分, 要求学生不仅有较强的理论知识, 还需要有动手解决实际问题的 能力[4]。为此, 成立教练员队伍, 注意教师的专业、年龄和特长的结合, 把年轻教师的新方法和老教师的 丰富经验充分结合, 实现互补。其中主教练为训练工作制定秩序渐进的训练计划, 进行明确的分工, 确保 每位教练都有明确的训练目标及任务, 提高训练效率。项目指导老师要研读上一年度大赛各项目评分细则, 根据细则每一环节要求、采分点, 制定好培训学生的详细方案, 使得训练在有序、有章中顺利进行。

另外, 我校出台了系列鼓励措施, 有计划地将教师特别是中、青年技能大赛指导教师按照专业特点和 进修意向分批分次送到各个岗位培训进修、学习考察或安排到生产、管理第一线进行实践, 使指导教师成 为既精通专业理论知识, 又熟悉专业技能的 “双师” 。化工生产技术技能大赛教练组成员专业实力得到明 显提高, 其中两人具有国家级化工技能竞赛裁判资质, 两人通过了化工总控工高级技师培训考核。教练组 整体实践技能水平得到明显提升。

\section{3 制定科学合理训练计划}

科学、详实的训练计划是保证训练质量的重要环节。为此, 我们制定了阶段性训练计划。

培训计划分五个阶段进行：第一阶段为适应性培训：面向化学工程学院所有专业学员初试、选拔; 第 二阶段为集中性训练、考核; 第三阶段针对性训练，6人 2 组训练; 第四阶段四位队员竞争集训; 第五阶段 赛前团队磨合、培训指导。

第一阶段：适应性培训。在每年的9月底, 分管领导要求一、二年级班主任在班级做大赛训练报名动 员工作, 学生根据自己兴趣、爱好报名。由于报名主体是各科专业课还没学习大一学生, 要对报名学生进 行单元操作仿真简单培训, 考核内容为基础化学相关知识理论、单元操作仿真, 选拔有较强理论知识和仿 真操作能力的选手。学生可根据自己的需要, 进入开放的仿真机房进行相应的训练。初试考核完毕, 确定 入围选手, 然后认真听取各任课教师的评价, 由教练组老师按照 $1: 3$ 的比例选拔参赛选手, 确保获选选手 德才兼备, 人数最好是 3 的倍数。

第二阶段：集中性训练。摸底考试，考查学生自学情况（理论和仿真）。考核结果能表明学生自学努 力程度、参加大赛的欲望。点评学生目前个人情况, 向学生讲清楚假期集训是一项苦差事, 让学生自由组 合分成三人一队, 每小队成员自己推荐队长。小队长之间协商, 制定出每小队训练计划（要求每小队每天 保证做一遍精馏), 同时要求每位学生制定自己的学习训练计划及预期要达到的目标。修改补充学生训练 计划, 并向学生提出假期培训要求、考核要求及考核时间。根据教练组老师专业、特长进行项目培训分工, 每个训练项目确定指导教师, 项目指导教师做到用心指导, 了解每位学生本项目实际情况, 并做好每次考 核后的点评总结工作。每天保证有指导老师指导、检查学生训练, 在训练中引入了竞争机制, 采用末位淘 汰的方式淘汰成绩不好的学生, 保留6名选手形成两队, 构成对抗。

第三阶段, 整体提高期。经过集中训练, 进入此阶段训练学生有良好自制力及自学能力, 各项技能达 到了较高水平。两队队长根据自己队成员课余时间情况制定本阶段训练计划, 星期四下午及周末训练仿真、 精馏, 理论靠学生课余零散时间自学。此阶段要提高竞争机制, 加强考核力度, 期间理论、仿真各考六次, 精馏考核两次, 学生整体水平明显提高。但发现个别学生毅力、信心不足, 小组成员不够和谐情况。为此, 根据考核结果, 主教练老师找每位学生谈话, 分析学生优点及不足, 肯定学生努力成绩, 点出其存在不足。 训练约 20 天淘汰 2 名队员, 公布 4 名队员组成的训练小组。 
第四阶段, 明确告诉学生确定参加国赛选手时间。强调本阶段的训练要集中每个人的智慧, 一定要互 相讨论, 扬长避短, 为我们最后能参赛学员注入实力, 因而说, 无论是谁走出去, 这个团体都凝结着我们 四个人的智慧、实力, 都是我们四人的自豪, 能跨入本阶段训练的你们都是非常优秀的。采用竞争机制, 本阶段每位学生都刻苦、用心训练。共进行6次理论、6次仿真、2次精馏考核, 其中两次全程考核邀请了 学院的领导、专业教师到训练现场担任裁判, 科学地评价反映在每名学生身上的训练成果。根据学生该阶 段成绩稳定性、团队协调性最后确定了 3 名队员进入最后冲刺阶段训练。

第五阶段, 强化冲刺期, 一般国赛前 40 天。学生停课进入强化训练, 查缺补漏, 保持成绩平稳上升。 模拟正式大赛的全过程, 分解大赛考核指标, 让学生模拟角色在规定时间内完成所有竞赛任务。在学院领 导支持、关心下, 我们与省内兄弟院校开展积极的互访互学工作, 到兄弟院校进行精馏设备训练, 消除了 队员对新设备恐惧心理, 调整了队员的竞技状态。在相互学习过程中发现问题、解决问题, 确保队员在全 国职业院校技能大赛实战过程中，保持良好的竞技状况。

\section{4 训练体会及经验}

目前, 全国职业院校技能大赛是国内最高层次的面向所有中高职院校学生的赛事活动, 被誉为职教领 域的 “高考”。指导学生大赛训练能取得优良的成绩，主要体会有如下几点：

\section{1 提高大赛重视度是大赛取得好成绩的必备条件}

领导将每年一度的大赛培训工作列为重点工作之一。向全体教职工灌输 “以赛促教, 以赛促学”工作 理念, 要求将大赛知识融入每门学科的教学过程中, 要借大赛媒介提升全体师生技能水平, 打造精品教师 及学生。大赛培训整个过程得到学院领导关爱、支持, 由学院领导牵头、带队到有大赛设备的兄弟院校进 行碰商、学习, 即消除了师生对设备陌生的畏惧感, 又弥补了师生技能不足缺口。学院内各教研室、实训 室中心、办公室等部门配合非常默契, 服务工作有条不紊, 使师生在心情愉悦状态下进行赛前培训准备工 作。

\section{2 激发学生参赛兴趣, 对大赛培训起到事半功倍作用}

多年训练经验证明, 学生强烈参赛欲望是取得优异成绩内动力。在这样心理驱动下, 学生会倍增努力、 钻研, 也表现出良好的自学毅力和很好的自控力。激发学生参赛兴趣非常重要。加大宣传全国技能大赛的 意义和作用, 如天津市对在全国职业院校技能大赛中，凡有单位接收的大赛高职组获得二等奖以上的参赛 选手都可以当年办理户籍进津手续, 获得三等奖的选手在津工作 2 年后也可办理户籍进津手续; 健全学生 激励办法, 实施 “以赛代考”、 “学分替换” 改革, 长期开展学生技能竞赛促学风建设活动, 竞赛取得成绩 者可直接折算成学分, 免修相关课程, 同时将学生参加技能竞赛、技能志愿活动纳入学期综合测评, 与学 生的评优评先评奖、入党和推荐就业紧密结合, 激励学生形成 “学比帮赶超”的良好风气。

\section{3 教练老师技能、管理水平是大赛获胜的前提保障}

俗话讲 “名师出高徒”。职业院校的技能大赛既能考察学生的综合能力, 又能反映出职业院校的教学 水平和师资水平。选手之间较量的背后, 其实也是教练之间的较量。化工生产技术技能比赛项目都是化工 企业生产的实景再现, 代表了化工企业生产的新要求、新方向。因而, 指导教师要开阔视野, 更新理念, 关注职业发展的理论和科技发展的前沿, 关注职业领域的最新技术变化, 积极主动参与提升自己实践技能 活动中去。如要走出去, 到企业锻炼, 与兄弟院校指导教师学习, 提高专业能力, 积累实践经验; 请进来, 
聘请企业及兄弟院校的一流技师, 学习先进, 缩小差距, 实现新突破。通过参与指导技能大赛, 全面了解 和具体掌握化工生产技术操作流程和操作规范, 促使教师更好、更快提高自身业务水平, 特别是实践能力, 进而全面提升教学团队整体素质。

\section{4 队员良好心理素质是大赛获胜最关键因素}

学生是赛场上的主体, 学生的心理状态和应变能力是比赛能否取得好成绩最关键的因素。到陌生环境, 队员经常表现出紧张的情绪, 发挥不出已有训练水平。这些是指导老师选择队员必须要考虑的因素。在竞 赛场上, 不求学生超常发挥, 只求学生能正常发挥。精馏执裁中遇到某参赛团队, 队员合作默契, 操作熟 练, 距离精馏考核结束仅差十几分钟时, 一楼 2 号队员因慌乱, 想开冷却水阀却错开成排塔釜液阀门, 造 成人为干烧事故, 仪器报警, 被裁判强制停车。可见, 队员心理素质非常关键。为此, 采用变换训练环境 和场所以提高选手适应性; 模拟大赛考核程序, 请相关专业的老师和学生集体观摩选手练习, 打分, 增强 选手的比赛适应性和灵活性。另外, 在大赛前, 教师不要给学生施加压力, 要求学生以平常心对待。为了 克服紧张心理, 除了要有扎实的训练功底外, 更重要的是学生要有良好的心理素质, 在临考阶段, 做好学 生的心理辅导至关重要。

\section{5 良好的团队合作精神是大赛获胜的法宝}

要在竞赛中取得好成绩，应用能力是关键。此外，这种能力不是反映在参赛选手的个体上，而是反映 在参赛学生的群体上。

化工生产技术技能大赛精馏操作要现场操作, 是团体项目。精馏操作要求参赛院校选手密切配合, 根 据规定的操作规程进行乙醇一水混合溶液的精馏分离操作，对产品质量[5]、产量、操作时间、仪表使用、 系统稳定性控制、实际生产中的成本等方面加以考核, 要求进行开车前准备、预处理、正常操作、停车, 竞赛操作时间为 90 分钟。在培训中, 我们的学生一直以小团队的形式组织学习、训练, 每次的任务都由小 组成员自行分工，协作完成。他们个人的智慧会集中起来，完成从个人思考到集体讨论、工作的过程。在 这个过程中每个学生有更多的机会发挥自己所长, 吸收别人所长, 再进行交流、切磋, 这样他们的思考 水平、应用能力得到提高。合作学习有利于培养学生的协作精神、团队观念和交流能力, 并在思想的碰撞 中迸发创新的火花。

\section{5 结语}

在全国职业院校技能大赛的带动下，职业院校办学方向需要瞄准企业对技能型人才的需求状况，实现 培养的学生学有所成, 学以致用, 提升学生的职业能力; 同时大赛也直接惠及到职业院校的一些专业教师, 促进了学校之间的交流与合作，让教师感受到成为双师型教师既是学生参加大赛的需要，同时也是自身发 展的需要。

\section{参考文献:}

[1］黄瑞民，杨熙．化工总控工培训模式的探索 $[\mathrm{J}$ ．科技信息，2012，(32)：673.

[2] 朱江. 职业院校化工总控工培养途径探索 [J]. 新疆职业教育研究，2011，(01)：58-60.

[3] 贺新，刘媛．化工总控工职业技能鉴定应知试题集 [M]．第一版本．化学工业出版社：2010.

[4] 贺新, 薛叙明, 刘长春. 高职学生职业技能大赛的培训研究 一一以化工总控工为例 [J]. 化工时刊, 2010, 24(12) : 75-77.

[5] 朱巧风，慕苗. 中职化工总控工培养途径一一化工生产技术技能大赛为例 [J]. 广东化工，2013，40(18)：169. 


\section{References}

[1] R.M.Huang and X.Yang: Exploration of the Training Mode of Master-Control Technical Personnel of Chemical General Industry[J], Science \& Technology Information, 2012, (32): 673.(In Chinese)

[2] J.Zhu: On Cultivation of Master-Control Technical Personnel of Chemical Industry in Higher Vocational Schools[J], Vocational Education Research in Xinjiang, 2011,(01): 58-60.(In Chinese)

[3] X.He and Y.Liu: A Test Question Set of Professional Skills Identification of Master-Control Technical Personnel of Chemical General Industry[M], First Edition: Chemical Industry Press, 2010.(In Chinese)

[4] X.He, X.M.Xue and C.C.Liu: A Study on the Vocational Skills Competition of Higher Vocational Students - Taking the Master-Control Technical Personnel of Chemical General Industry as the Example[J], Chemical Industry Times, 2010, 24(12):75-77.(In Chinese)

[5] Q.F.Zhu and M.Mu: On Cultivation of Master-Control Technical Personnel of Chemical Industry in Middle Vocational Schools - Take the Megagame of Chemical Engineering Production as an Example[J], Guangdong Chemical Industry, 2013, 40(18): 169.(In Chinese) 